\title{
Composição físico-químico de vinhos de mesa brancos elaborados no Planalto Norte Catarinense, safra 2020
}

\author{
Physicochemical composition of white table wines produced in the Planalto Norte Catarinense, \\ 2020 vintage
}

Composición fisicoquímica de vinos blancos de mesa elaborados en el Planalto Norte Catarinense, cosecha 2020

\section{Resumo}

Apesar de haver produtores de uva e vinho de mesa na região do Planalto Norte Catarinense, análises da composição físico-químicas dos produtos não são feitas pelos produtores. Nesse contexto, tem-se como objetivo deste trabalho realizar a caracterização físico-química dos vinhos elaborados no Planalto Norte Catarinense, verificando se vinhos de mesa elaborados na região se enquadram nos padrões físico-químicos exigidos pela legislação nacional vigente. Os vinhos de mesa brancos foram coletados de oito vitivinicultores, sendo estas amostras da safra 2020. As análises físico-químicas foram realizadas em setembro de 2020, no Laboratório de Análises Físico-químicas do Instituto Federal de Santa Catarina -Canoinhas. As variáveis avaliadas foram: densidade relativa, acidez total, sólidos solúveis, $\mathrm{pH}$ e coloração dos vinhos. A variável sólidos solúveis apresentou valor médio de $6,6^{\circ}$ Brix. O valor médio para a densidade relativa foi de 0,990 . Os valores referentes a variável acidez total apresentaram valores médios de 74,3 meq L-1. O valor médio para o pH foi de 3,04 para as amostras, com intervalo de valores de 2,93 e 3,30. Os valores referentes a variável coloração dos vinhos (Abs $520 \mathrm{~nm}$ ) apresentaram valor médio de 0,740. Os resultados das análises físico-químicos estão de acordo com índices indicados na literatura e na legislação brasileira vigente, e as análises físico-químicas dos vinhos elaborados na região do Planalto Norte Catarinense devem ser realizadas a cada safra, com objetivo de acompanhar a evolução da qualidade dos vinhos elaborados na região, bem como verificar se estes apresentam padrões mínimos de qualidade exigidos pela legislação brasileira vigente.

Palavras-chave: Vitis labrusca L.; Acidez total; Coloração dos vinhos; Densidade relativa.

\begin{abstract}
Although there are grape and table wine producers in the Planalto Norte region of Santa Catarina, analyzes of the physicochemical composition of the products are not carried out by the producers. In this context, the objective of this work is to carry out the physical-chemical characterization of wines produced in the Planalto Norte Santa Catarina, verifying whether table wines produced in the region meet the physical-chemical standards required by current
\end{abstract}


national legislation. The white table wines were collected from eight winemakers, these being samples from the 2020 harvest. The physical-chemical analyzes were carried out in September 2020, at the Physical-chemical Analysis Laboratory of the Federal Institute of Santa Catarina -Canoinhas. The variables evaluated were: relative density, total acidity, soluble solids, $\mathrm{pH}$ and wine color. The soluble solids variable had an average value of $6.6^{\circ} \mathrm{Brix}$. The mean value for relative density was 0.990 . Values for the total acidity variable had mean values of 74.3 meq L-1. The mean value for $\mathrm{pH}$ was 3.04 for the samples, with a range of values of 2.93 and 3.30. Values for the variable color of wines (Abs $520 \mathrm{~nm}$ ) had an average value of 0.740 . The results of the physicochemical analyzes are in accordance with indices indicated in the literature and in the current Brazilian legislation, and the physicochemical analyzes of wines produced in the Planalto Norte region of Santa Catarina must be carried out at each harvest, in order to monitor the evolution of the quality of wines produced in the region, as well as verifying if they present the minimum quality standards required by current Brazilian legislation.

Keywords: Vitis labrusca L.; Total acidity; Wine color; Relative density.

\section{Resumen}

Aunque hay productores de uva y vino de mesa en la región de Planalto Norte de Santa Catarina, los análisis de la composición fisicoquímica de los productos no son realizados por los productores. En este contexto, el objetivo de este trabajo es realizar la caracterización fisicoquímica de los vinos producidos en el Planalto Norte Catarinense, verificando si los vinos de mesa producidos en la región cumplen con los estándares fisicoquímicos exigidos por la legislación nacional vigente. Se recolectaron vinos blancos de mesa de ocho viticultores, siendo estos muestras de la cosecha de 2020. Los análisis físico-químicos se realizaron en septiembre de 2020, en el Laboratorio de Análisis Físico-Químico del Instituto Federal de Santa Catarina - Canoinhas. Las variables evaluadas fueron: densidad relativa, acidez total, sólidos solubles, $\mathrm{pH}$ y color del vino. La variable sólidos solubles presentó un valor promedio de 6,6 ${ }^{\circ}$ Brix. El valor medio de la densidad relativa fue de 0,990. Los valores referentes a la variable acidez total presentaron valores promedio de 74,3 meq L-1. El valor promedio de $\mathrm{pH}$ fue de 3,04 para las muestras, con un rango de valores entre 2,93 y 3,30. Los valores referentes a la variable color del vino (Abs $520 \mathrm{~nm}$ ) presentaron un valor promedio de 0.740 . Los resultados de los análisis físico-químicos están de acuerdo con los índices indicados en la literatura y en la legislación brasileña vigente, y los análisis físico-químicos de los vinos producidos en la región del Planalto Norte Catarinense deben ser realizados en cada cosecha, con el fin de acompañar la evolución de la calidad de los vinos producidos en la región, así como verificar si presentan los estándares mínimos de calidad exigidos por la legislación brasileña vigente.

Palabras clave: Vitis labrusca L.; Acidez total; Color del vino; Densidad relativa.

\section{Introdução}

Tem-se a diversidade como marca da viticultura brasileira diversidade, tanto de material genético quanto de regiões produtoras (Carmargo et al. 2011), e nessa diversidade de regiões surge o Planalto Norte Catarinense com grande potencial no cultivo de uvas Vitis labrusca para processamento (Wurz et al., 2020a), pois de acordo com Brighenti et al. (2018), observa-se uma demanda por estas variedades no estado de Santa Catarina. Atualmente, o processamento de uvas é concentrado em poucos municípios de Santa Catarina, com destaque para as variedades híbridas e americana: Isabel, Bordô e Niágara branca (Empresa de Pesquisa e Extensão Rural de Santa Catarina, 2019).

A região do Planalto Norte Catarinense caracteriza-se por apresentar grande vocação agrícola e, nesse contexto, a viticultura apresenta grande potencial de exploração de crescimento, podendo gerar renda e emprego, e devido às condições edafoclimáticas do Planalto Norte Catarinense, a cultura da videira apresenta grande potencial de cultivo na região, em especial as variedades americanas, destinadas ao consumo in natura, elaboração de suco de uva e elaboração de vinhos de mesa, além disso, (Wurz et al., 2020b).

O crescimento da viticultura é de suma relevância para a sustentabilidade das famílias no meio rural, em várias regiões do Brasil (Silva et al., 2019). A viticultura no Planalto Norte Catarinense tem como principal objetivo a diversificação da pequena propriedade, fornecendo uma nova fonte de renda ao produtor, visando à produção de uvas para consumo in natura, bem como, a produção de uvas para o processamento, vinhos e suco de uva (Wurz et al., 2021a). De acordo com Wurz et al. (2021b), apesar de haver produtores de uva e vinho de mesa na região do Planalto Norte Catarinense, análises da composição físico-químicas dos produtos não são feitas pelos produtores, não havendo, portanto, dados analíticos e científicos dos padrões de qualidade dos vinhos elaborados. 
A qualidade de um vinho pode ser influenciada por uma série de fatores como as condições sanitárias da uva, a tecnologia de vinificação utilizada (Lee et al., 2006), o tipo do solo, as condições climáticas e o manejo da videira (Chavarria et al., 2008). Esses fatores são responsáveis por determinar as propriedades químicas do vinho e proporcionar características sensoriais de qualidade (Castilhos \& Del Bianchi, 2012).

A qualidade de um vinho pode ser determinada por suas características físico-químicas (Raposo et al., 2018), possibilitando a identificação da qualidade dos vinhos (Castilhos \& Del Bianchi, 2011), além de permitir a verificação da aptidão comercial dos produtos, estando sua composição dentro dos limites estabelecidos pela legislação (Brito et al., 2020). Os parâmetros físico-químicos dos vinhos permitem avaliar o controle na elaboração, que podem ser relacionados aos principais fatores tecnológicos empregados durante a sua produção (Santos, 2006).

Nesse contexto, tem-se como objetivo deste trabalho realizar a caracterização físico-química dos vinhos elaborados no Planalto Norte Catarinense, verificando se vinhos de mesa elaborados na região se enquadram nos padrões físico-químicos exigidos pela legislação nacional vigente.

\section{Metodologia}

O presente trabalho trata-se de uma avaliação físico-química laboratorial, e foi realizado no Instituto Federal de Santa Catarina - Câmpus Canoinhas, no ano de 2020. Os vinhos de mesa brancos foram coletados de oito vitivinicultores do Planalto Norte Catarinense, sendo estas amostras da safra 2020. Coletou-se três garrafas de $750 \mathrm{ml}$ de cada amostra, sendo estas codificadas para não serem identificado os vitivinicultores, na qual duas foram utilizadas para as análises físico-químicas e uma garrafa para ser armazenada como contraprova. Após a coleta das amostras, estas foram acondicionadas no laboratório de análise físico-química do IFSC Campus Canoinhas, com temperatura $\left(16^{\circ} \mathrm{C}\right)$ e umidade $(75 \%)$ relativa controlada e protegida da luminosidade, para evitar alterações em sua composição físico-química.

As análises físico-químicas foram realizadas em setembro de 2020, no Laboratório de Análises Físico-químicas do Instituto Federal de Santa Catarina - Câmpus Canoinhas. As análises foram realizadas em triplicata, e as variáveis avaliadas foram: densidade relativa, acidez total titulável, sólidos solúveis, $\mathrm{pH}$ e coloração dos vinhos (Abs $520 \mathrm{~nm}$ ), através de metodologias oficiais da Organização Internacional da Vinha e do Vinho (Oiv, 2012).

Para determinar o teor de sólidos solúveis (SS) utilizou-se um refratômetro digital para açúcar, modelo ITREFD-45, sendo os resultados expressos em ${ }^{\circ}$ Brix. A acidez total (AT) foi obtida através da titulação do mosto com solução alcalina padronizada de hidróxido de sódio $0,1 \mathrm{~N}$, utilizando como indicador o azul de bromotimol, sendo os resultados expressos em meq L-1. O potencial hidrogeniônico $(\mathrm{pH})$ foi registrado por meio de um potenciômetro marca Impac, após calibração em soluções tampões conhecidos de pH 4,0 e 7,0. A densidade foi determinado pelo método densimétrico. A coloração foi determinada pelo método de espectrofotometria, descrito por Rizzon (2010), no comprimento de onda $520 \mathrm{~nm}$.

Com os dados obtidos, foram elaborados os gráficos e tabelas (VMB = Vinho de Mesa Branco, sendo as amostras numeradas de VMB 01 a VMB 08, e média dos valores das oito amostras, representando as características físico-químicas dos vinhos.

Os dados foram digitados, tabulados e com auxílio do software Excel 2010 realizou-se a elaboração de gráficos para o desenvolvimento de uma análise descritiva dos dados obtidos nas amostras verificadas.

\section{Resultados e Discussão}

Os dados referentes ao conteúdo de sólidos solúveis das amostras de vinhos de mesa branco elaborados na região do Planalto Norte Catarinense estão descritos na Figura 1. Observou-se valores médios para esta variável de 6,6 ${ }^{\circ}$ Brix, contudo, com valores variando de 5,3 á 7,6 ${ }^{\circ}$ Brix. De acordo com Wurz et al. (2021a), não é comum quantificar a variável sólidos 
solúveis. No entanto, no presente trabalho, realizou-se a avaliação, para auxiliar na identificação de amostras que ocorreram a adição de açúcar, após a finalização do processo de elaboração, caracterizando-se vinhos suaves.

Pelos resultados demonstrados percebe-se que os vinhos não apresentam valores elevadas de sólidos solúveis, indicando a não adição de açúcar, ao final do processo de fermentação para as oito amostras avaliadas, e de acordo com Reis (2016), os teores de sólidos solúveis podem sofrer influência em função das condições de cultivo e da variedade.

Figura 1. Conteúdo de sólidos solúveis de amostras de vinhos de mesa brancos elaborados na região do Planalto Norte Catarinense. Canoinhas, 2020.

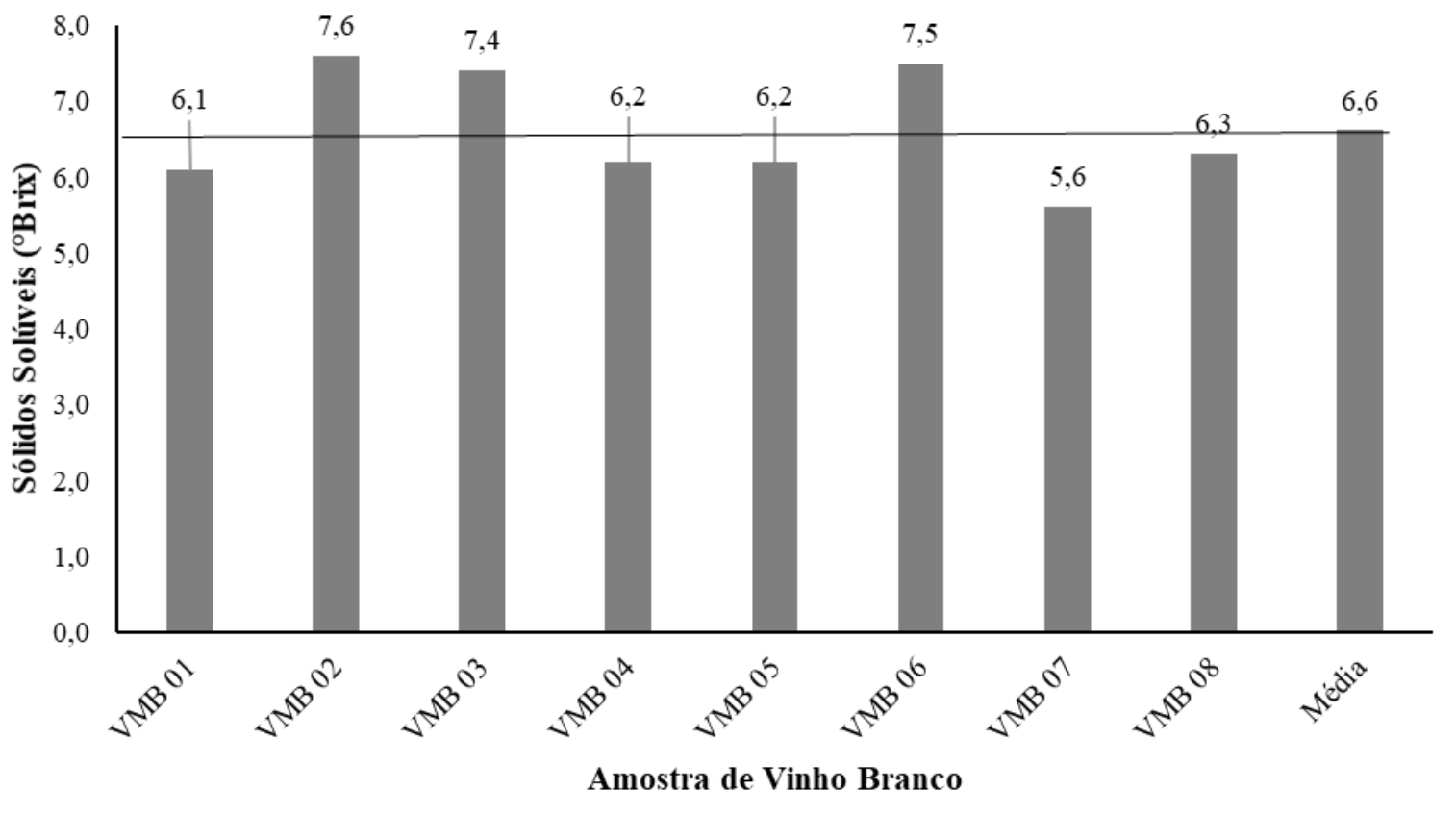

Fonte: Autores.

Na Figura 2 estão descritos os valores relacionados a variável densidade relativa. O valor médio para a variável densidade relativa foi de 0,990 . Observa-se valores similares para as oito amostras, com valores variando de 0,988 a 0,991. Os dados referentes a densidade relativa corroboram com interpretação dos dados referentes aos sólidos solúveis, a qual indicam que não houve adição de açúcar nas amostras avaliadas após o processo de fermentação estar concluído, sendo portanto, oito amostras de vinhos de mesa branco seco.

De acordo com Silva et al. (2015), em experimento com amostras de vinho branco, obteve médias próximas a 1,000, já Wurz e al. (2021a), observou valores médios de 0,998. Os vinhos com valores superiores a 1,000 indicam maior quantidade de açúcar (Costa, 2017), e no presente estudo nenhuma amostra apresentou valor de densidade relativa superior a 1,000, indicando serem vinhos secos. Nos vinhos completamente fermentados e isentos de açúcares, geralmente, a densidade é inferior a 1,000 e os vinhos apresentam um teor alcoólico maior.

Além disso, a densidade relativa e o teor alcoólico correlacionam-se, sendo que à medida que as concentrações de densidade relativa diminuem, os teores alcoólicos aumentam (Manfroi et al., 2010; Oliveira et al., 2011). 
Figura 2. Densidade relativa de amostras de vinhos de mesa brancos elaborados na região do Planalto Norte Catarinense. Canoinhas, 2020.

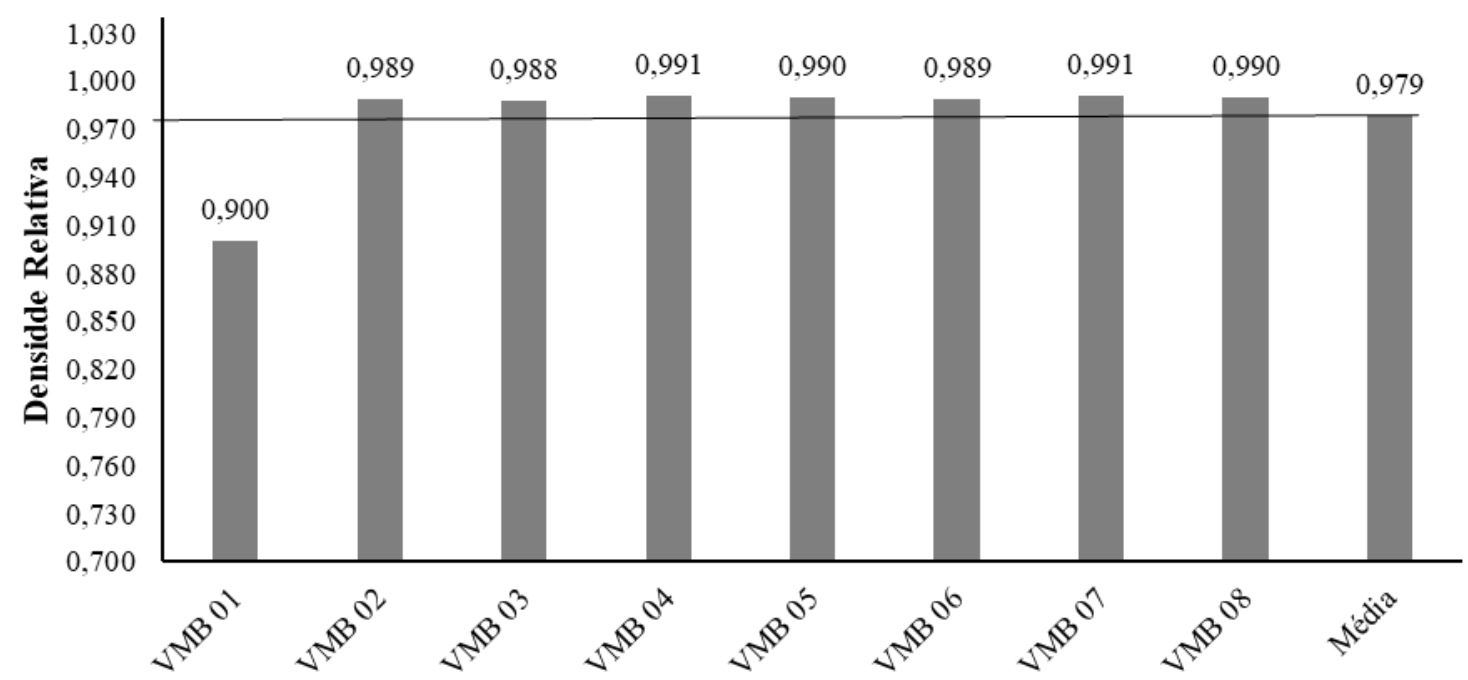

Amostra de Vinho Branco

Fonte: Autores.

Os principais ácidos orgânicos presentes no vinho são os ácidos tartárico, málico e cítrico, que são ácidos presentes na uva, e os ácidos succínico, lático e acético, os quais são provenientes da fermentação (Lovato \& Wagner, 2008; Rizzon, 2010). Os valores referentes a variável acidez total estão descritos na Figura 3, apresentando valores médio de 74,3 meq L ${ }^{-1}$. O menor valor de acidez total foi observado na amostra VMB 01, apresentando valore de 55,0 meq L ${ }^{-1}$, e os maiores valores observados nas amostras VMB 05 e VMB 07, com valores de 88,0 e 90,0 meq L-1, respectivamente.

De acordo com Wurz et al. (2021a), para a variável acidez total titulável dos vinhos de mesa, o valor ideal deve estar entre 40 meq $\mathrm{L}^{-1}$ até $130 \mathrm{meq} \mathrm{L}^{-1}$, portanto, no presente estudo os valores enquadram-se na faixa ideal de acidez total.

Uma acidez equilibrada é importante, caso seja muito ácido, terá um gosto muito ácido, e baixos valores de acidez podem deixar a bebida mais suscetível à contaminação por microrganismos. Castilhos \& Del Bianchini (2011) obtiveram valores entre 93 e $121 \mathrm{meq} \mathrm{L}^{-1}$, para amostras de vinhos brancos. 
Figura 3. Conteúdo de acidez total titulável de amostras de vinhos de mesa brancos elaborados na região do Planalto Norte Catarinense. Canoinhas, 2020.

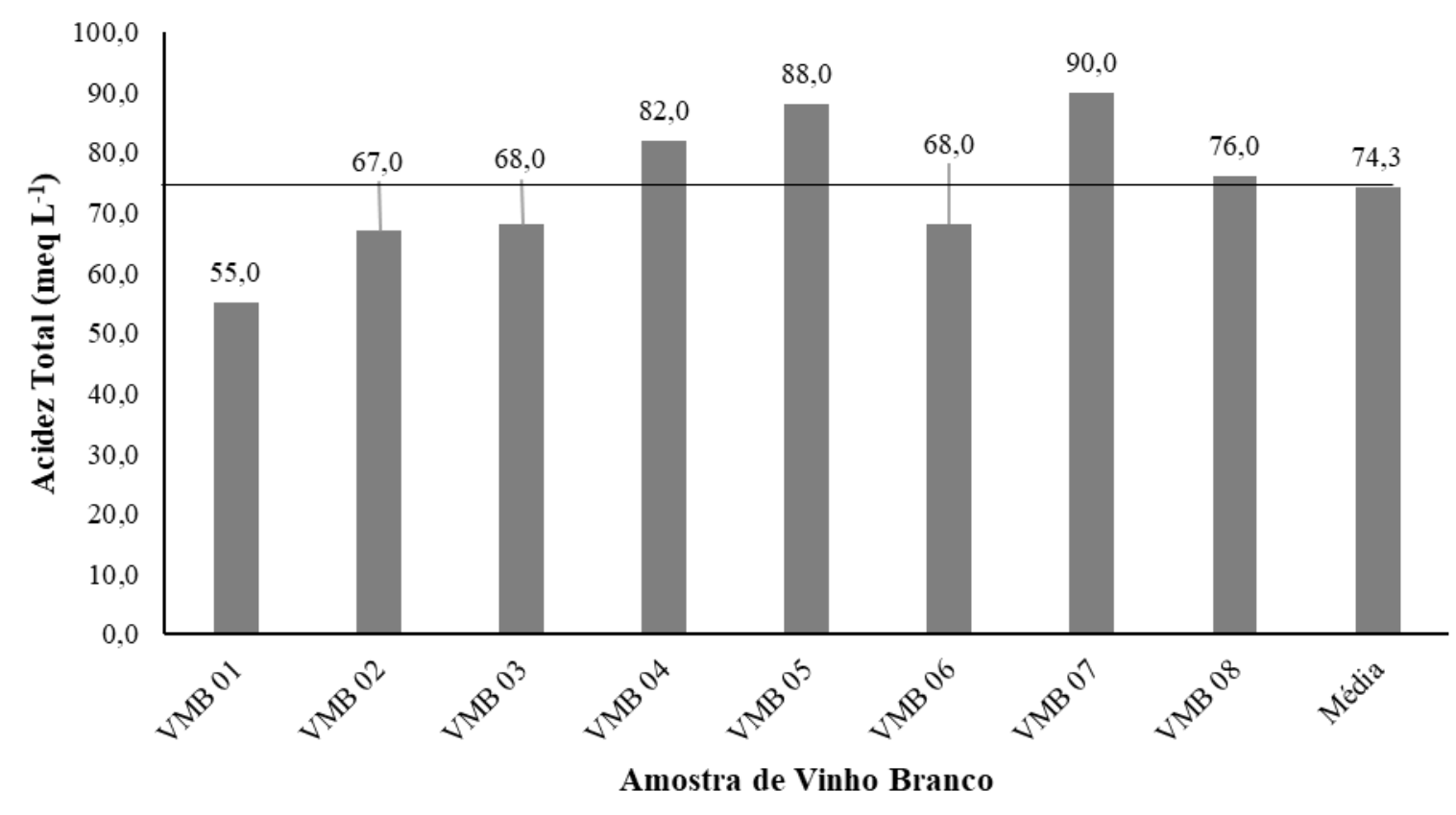

Fonte: Autores.

Os valores referentes a variável $\mathrm{pH}$ das amostras de vinhos de mesa branco elaborados na Região do Planalto Norte Catarinense estão descritos na Figura 4. O valor médio para o pH foi de 3,04 para as amostras, havendo um intervalo de valores de 2,93 e 3,30. Para o pH o valor ideal varia de 3,0 até 3,6, dependendo do tipo de vinho, branco ou tinto, da cultivar da uva, e da safra (Moraes \& Locatelli, 2010), indicando que duas amostras estão com valores inferiores a faixa ideal da variável $\mathrm{pH}$.

De acordo com Bender et al. (2017), O pH não é uma variável com limites determinados pela legislação brasileira, no entanto, é importante pois apresenta influência no sabor e na proporção entre $\mathrm{SO}_{2}$ livre e combinado, bem como no crescimento e sobrevivência de microrganismos ao longo do processo de elaboração do vinho. 
Figura 4. Valores de $\mathrm{pH}$ de amostras de vinhos de mesa brancos elaborados na região do Planalto Norte Catarinense. Canoinhas, 2020.

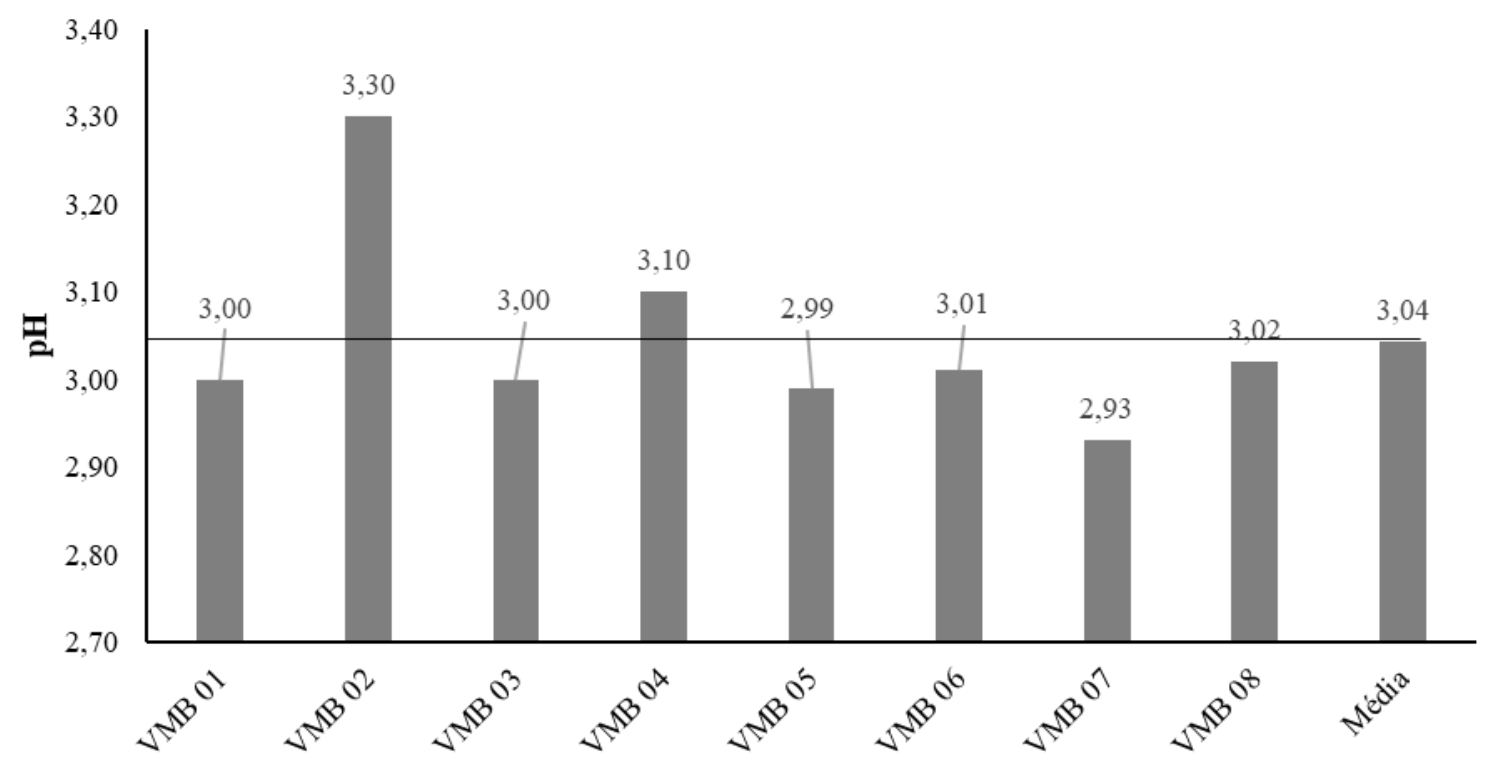

Amostra de Vinho Branco

Fonte: Autores.

Os valores referentes a variável coloração dos vinhos (Abs $520 \mathrm{~nm}$ ) apresentaram valor médio de 0,740, havendo variação entre as amostras de vinhos de mesa branco, com o menor valor observado na amostra VMB 04 (0,705), e o maior valor observado na amostra VMB 02 (0,774). De acordo com Wurz et al. (2021a), a coloração $520 \mathrm{~nm}$ está relacionada com a coloração amarela, e quanto maior o seu valor, maior a coloração amarela, havendo uma correlação entre a maior intensidade de coloração amarela e a oxidação do produto. Ou seja, quanto menor o valor de coloração dos vinhos brancos, menor a oxidação das amostras avaliadas.

A elaboração de vinhos brancos é um desafio para pequenos produtores, pois são vinhos que estão mais sujeitos aos processos oxidativos, exigindo maiores conhecimentos técnicos e infraestrutura para a elaboração de vinhos de elevada qualidade (Wurz et al., 2021a). 
Figura 5. Coloração de vinhos (Abs $520 \mathrm{~nm}$ ) de amostras de vinhos de mesa brancos elaborados na região do Planalto Norte Catarinense. Canoinhas, 2020.

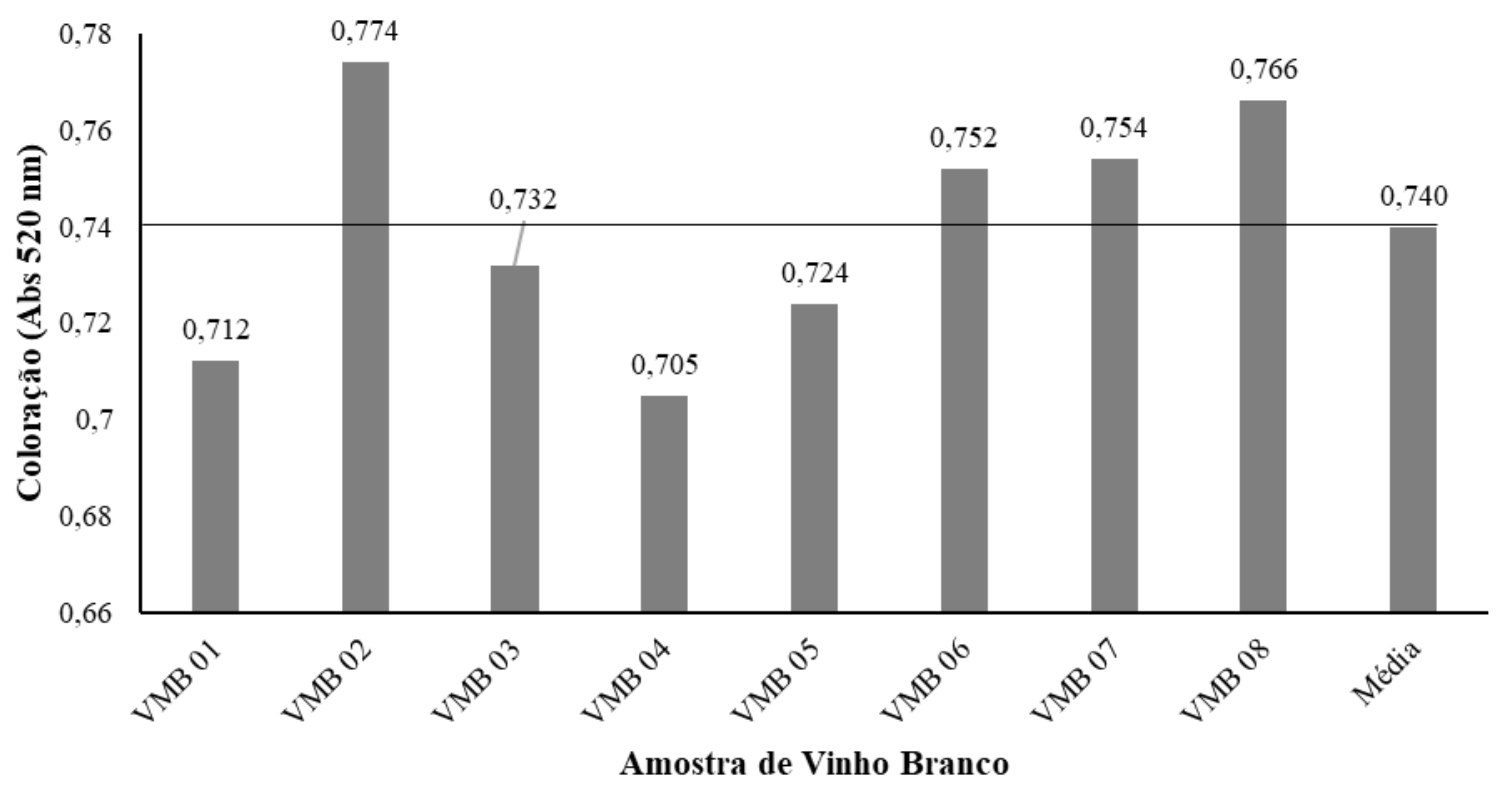

Fonte: Autores.

\section{Conclusão}

De acordo com os dados referentes ao perfil físico-químico e sensorial de vinhos de mesa brando, conclui-se que a região do Planalto Norte Catarinense apresenta potencial para elaboração de vinhos de mesa branco de qualidade, verificandose a elaboração de vinhos secos.

Os resultados das análises físico-químicos estão de acordo com índices indicados na literatura e na legislação brasileira vigente, e as análises físico-químicas dos vinhos elaborados na região do Planalto Norte Catarinense devem ser realizadas a cada safra, com objetivo de acompanhar a evolução da qualidade dos vinhos elaborados na região, bem como verificar se estes apresentam padrões mínimos de qualidade exigidos pela legislação brasileira vigente.

\section{Referências}

Bender, A., Silva, R. S., Malgarim, M. B., Martinez, J. F. \& Brasil Costa, V. (2017). Avaliação Físico-Química e Compostos Bioativos de Vinho Tinto Colonial produzido em São Lourenço do Sul (RS). Revista Eletrônica Científica UERGS, 3(2), 249-265.

Brighenti, A. F., Allebradnt, R., Munhoz, B., Matos, D. P., Regina, M. A. \& Silva, A. L. (2018). Qualification of Bordô grape clones in Vale do Rio do Peixe, in the state of Santa Catarina, Brazil. Pesquisa Agropecuária Brasileira, Brasília, 53(7), 800-808.

Brito, F. L., Neves, N. A., Valente, M. E., Pantoja, L. \& Santos, A. S. (2020). Diagnóstico da qualidade química de vinhos produzidos na região Sul do estado de Minas Gerais. Research, Society and Development, 9(11), e3479119763.

Camargo, U. A., Tonietto, J. E. \& Hoffmann, A. (2011). Progressos na Viticultura Brasileira. Revista Brasileira de Fruticultura, $33,144-149$.

Castilhos, M. B. M. \& Bianchi, V. L. (2011). Caracterização físico-química e sensorial de vinhos brancos da região Noroeste de São Paulo. Revista Holos, 4, $148-158$.

Castilhos, M. B. M. \& Bianchi, V. L. (2012). Vinhos Tintos do Noroeste Paulista: relação entre perfis físico-químicos e sensorial. Revista Holos, 4, 80-89.

Chavarria, G., Santos, H. P., Zanus, M. C., Zorzan, C., \& Marodin, G. A. B. (2008). Caracterização físico-química do mosto e do vinho Moscato Giallo em videiras cultivadas sob cobertura de plástico. Pesquisa Agropecuária Brasileira, 43(7), 911-916.

Costa, E. K. (2017). Avaliação físico-química de vinhos artesanais produzidos na região Noroeste do Estado do Rio Grande do Sul. 2017. 21 p. Trabalho de Conclusão de Curso (Graduação em Farmácia) - Universidade Regional do Noroeste do Estado do Rio Grande do Sul - UNIJUÍ, Ijuí.

Epagri. (2019). Empresa de Pesquisa Agropecuária e Extensão Rural de Santa Catarina. Síntese Anual da agricultura de Santa Catarina 2017-2018. Disponível em http://webdoc.epagri.sc.gov.br/sintese.pdf>, acesso em 11 de novembro de 2021. 
Research, Society and Development, v. 11, n. 2, e9611225718, 2022

(CC BY 4.0) | ISSN 2525-3409 | DOI: http://dx.doi.org/10.33448/rsd-v11i2.25718

Lee, S. J., Lee, J. E., Kim, H. W., Kim, S. S., \& Koh, K. H. (2006). Development of Korean red wines using Vitis labrusca varieties: instrumental and sensory characterization. Food Chemistry, 94, 385-393.

Lovato, M. A. \& Wagner, R. (2012). Avaliação da qualidade do vinho de mesa suave por análises físico-químicas. Cadernos da Escola de Saúde, 8, 168-178.

Manfroi, V., Rizzon, L. A., Guerra, C. C.; Fialho, F. B., Dall'agnol, I., Ferri, V. C., \& Rombaldi, C. V. (2010). Influência de taninos enológicos em diferentes dosagens e épocas distintas de aplicação nas características físico químicas do vinho Cabernet Sauvignon. Ciência e Tecnologia de Alimentos, 30, 127-135.

Moraes, V. \& Locatelli, C. (2010). Vinho: uma revisão sobre a composição química e benefícios a saúde. Evidência, 10(1-2), 57-68.

Oiv. (2012). Recueil des méthodes internationales d'analyse des vins et des moûts. Office international de la vigne et du vin. Paris, 368.

Oliveira, L. C., Souza, S. O. \& Mamede, M. E. (2011). Avaliação das características físico-químicas e colorimétricas de vinhos finos de duas principais regiões vinícolas do Brasil. Revista Instituto Adolfo Lutz, 70(2), 158-167.

Raposo, R., Chinnici, F., Ruiz-Moreno, M. J., Puertas, B., Cuevas, F. J., Carbú, M., Guerrero, R. F., Ortíz-Somovilla, V., Moreno-Rojas, J. M. \& Cantos-Vilar, E. Sulfur free red wines through the use of grapevine shoots: Impact on the wine quality. Food Chemistry, 243, 453-460.

Reis, T. A. (2016). Elaboração, caracterização e análise sensorial de vinhos (Vitis spp.) de região subtropical. 2016. 107 p. Tese (Doutorado em Ciência dos Alimentos) - Universidade Federal de Lavras.

Rizzon, L. A. (2010). (ed.) Metodologia para análise de vinho. Brasília: Embrapa Informação Tecnológica, 120 p.

Santos, B. A. C. (2006). Compostos voláteis e qualidade dos vinhos secos jovens varietal Cabernet Sauvignon produzidos em diferentes regiões do Brasil. Campinas: 155p. Tese (Doutorado em Ciência de Alimentos) Faculdade de Engenharia de Alimentos, Universidade Estadual de Campinas

Silva, M. J., Tecchio, M. A., Moura, M. F., Brunelli, L. T., Imaizumi, V. M. \& Venturini Filho, G. (2015). Composição físico-química do mosto e do vinho branco de cultivares de videiras em resposta a porta-enxertos. Pesquisa Agropecuária Brasileira, 50(11), 1105-1113.

Wurz, D. A., Kowal, A. N., Almeida, R. S., Maciel, T. A., Oliveira, S., Nizer, M., Arendartchuck, C. \& Costa, S. T. (2020a). Quebra de dormência da videira 'Niágara Branca' com a utilização de cianamida hidrogenada no Planalto Norte Catarinense. Scientia Vitae, 10(31), 13-22.

Wurz, D. A., Maciel, T. A. \& Almeida, R. S. (2020b). "Concurso dos Melhores Vinhos e Sucos de Uva do Planalto Norte-catarinense - Edição 2019”. Revista Caminho Aberto, 7(13), 69-73.

Wurz, D. A. \& Jastrombek. (2021a) Caracterização físico-químico de vinhos brancos de mesa elaborados no Planalto Norte Catarinense. Revista Ifes Ciência, 7(1), 01-09.

Wurz, D. A., Jastrombek, J. M., Maciel, T. A., Almeida, R. S. \& Kowal, A. N. (2021b). Caracterização físico-químico de vinhos de mesa tintos elaborados na região do Planalto Norte Catarinense, safra 2019. Revisa Ciência e Inovação do IFFAR, 7(1), 1-16. 